\title{
Oligomeric-Induced Activity by Thienyl Pyrimidine Compounds Traps Prion Infectivity
}

\author{
Adeline Ayrolles-Torro, ${ }^{1,2,3}$ Thibaut Imberdis, ${ }^{1,2,3}$ Joan Torrent, ${ }^{1,2,3}$ Karine Toupet, ${ }^{1,2,3}$ Ilia V. Baskakov, ${ }^{4}$ \\ Guillaume Poncet-Montange, ${ }^{1,2,3}$ Catherine Grégoire, ${ }^{1,2,3}$ Françoise Roquet-Baneres, ${ }^{5}$ Sylvain Lehmann, ${ }^{6}$ \\ Didier Rognan, ${ }^{7}$ Martine Pugnière, ${ }^{5}$ Jean-Michel Verdier, ${ }^{1,2,3}$ and Véronique Perrier ${ }^{1,2,3}$ \\ ${ }^{1}$ Université Montpellier 2, Montpellier, F-34095 France, ${ }^{2}$ Inserm, Unité 710, Montpellier, F-34095 France, ${ }^{3}$ Ecole Pratique des Hautes Etudes, Paris, F-75007 \\ France, ${ }^{4}$ Center for Biomedical Engineering and Technology, Department of Anatomy and Neurobiology, University of Maryland School of Medicine, \\ Baltimore, Maryland 21201, 5Institut de Recherche en Cancérologie de Montpellier, Centre Régional de Lutte contre le Cancer, Val d'Aurelle-Paul \\ Lamarque, Inserm, Unité 896 -UM1, F-34298, France, ${ }^{6}$ Institut de Génétique Humaine, Centre National de la Recherche Scientifique (CNRS), Unité Propre \\ de Recherche 1142, Institut de Recherches en Biothérapie, Centre Hospitalier Universitaire de Montpellier, Université Montpellier 1, Montpellier, F-34000 \\ France, and 7Université de Strasbourg, Unité Mixte de Recherche 7200, CNRS, Illkirch, F-67400 France
}

Accumulation of $\operatorname{PrP}^{\mathrm{Sc}}$, an abnormal form of cellular prion protein (PrP), in the brain of animals and humans leads to fatal neurodegenerative disorders known as prion diseases. Limited protease digestion of $\operatorname{PrP}^{\mathrm{Sc}}$ produces a truncated form called $\operatorname{PrP}(27-30)$ that retains prion infectivity and is the main marker of disease targeted in most diagnostic tests. In the search for new anti-prion molecules, drug-screening assays on prion-infected murine cells have been oriented toward decreasing levels of $\operatorname{PrP}(27-30)$. In contrast, we screened for drugs promoting multimers of $\operatorname{PrP}(27-30)$, illustrating a possible stabilization of mouse $\operatorname{PrP}^{\mathrm{Sc}}$ species, because recent studies aiming to characterize the conformational stability of various prion strains showed that stable recombinant amyloids produced more stable prion strain, leading to longest incubation time. We identified a family of thienyl pyrimidine derivatives that induce SDS-resistant dimers and trimers of $\operatorname{PrP}(27-30)$. Bioassays performed on mice brain homogenates treated with these compounds showed that these thienyl pyrimidine derivatives diminished prion infectivity in vivo. Oligomeric-induced activity by thienyl pyrimidine compounds is a promising approach not only to understanding the pathogenesis of prions but also for prion diagnostics. This approach could be extended to other neurodegenerative "prionopathies," such as Alzheimer's, Huntington, or Parkinson's diseases.

\section{Introduction}

The hallmark of prion diseases is the deposition in the brain of $\mathrm{PrP}^{\mathrm{Sc}}$, an abnormal $\beta$-sheet-rich form of the cellular prion protein $\left(\mathrm{PrP}^{\mathrm{C}}\right)$ (Prusiner, 1982). According to the prion hypothesis, $\operatorname{PrP}^{\mathrm{Sc}}$ can trigger the autocatalytic conversion of $\operatorname{PrP}^{\mathrm{C}}$ into $\operatorname{PrP}^{\mathrm{Sc}}$, involving several $\mathrm{PrP}^{\mathrm{Sc}}$ pre-amyloid intermediates, generated through a complex mechanism of oligomerization (Silveira et al., 2005; DeMarco et al., 2006; Stöhr et al., 2008). The replication

Received Feb. 1, 2011; revised Aug. 8, 2011; accepted Aug. 10, 2011.

Author contributions: I.V.B., C.G., J.-M.V., and V.P. designed research; A.A.-T., T.I., J.T., K.T., I.V.B., G.P.-M., C.G., F.R.-B., M.P., and V.P. performed research; S.L. and D.R. contributed unpublished reagents/analytic tools; A.A.-T., T.I., J.T., K.T., G.P.-M., M.P., and V.P. analyzed data; V.P. wrote the paper.

The authors declare no competing financial interests.

This work was supported by Agence Nationale de Recherche Grant ANR-07-EMBP-025-01, Région Languedoc-Roussillon programme "Chercheurs d'Avenir" Grant 2010-Q-025, and Fondation Alliance Biosecure AAP-2009 "Priontrap." We thank Dr. J. Grassi for the kind gift of SAF monoclonal antibodies and Dr. C. Mourton-Gilles for the use of the Bio-Rad L3/A3 facility. We also thank Maria Teresa Alvarez and JacquesDamien Arnaud for their assistance with the platform L3/A3 (Montpellier Animaleries Network-Center for Breeding and Experimental Conditioning of Animal Models, Université Montpellier 2) and Dr. Thierry Baron for the gift of prion strains.

Correspondence should be addressed to either Véronique Perrier, Université Montpellier 2, Montpellier, F-34095 France or Jean-Michel Verdier, Ecole Pratique des Hautes Etudes, Paris, F75007, France. E-mail: veronique.perrier@univ-montp2.fr or jean-michel.verdier@ephe.sorbonne.fr.

G. Poncet-Montange's present address: Institute for Neurodegenerative Diseases, University of California, San Francisco, San Francisco, CA 94143-0518

DOI:10.1523/JNEUROSCI.0547-11.2011

Copyright $\odot 2011$ the authors $\quad 0270-6474 / 11 / 3114882-11 \$ 15.00 / 0$ cycle proceeds with the self-assembling of $\mathrm{PrP}^{\mathrm{Sc}}$ oligomers into proto-fibrils, which in turn grow into amyloid fibrils.

These different conformational forms can be specific targets for therapeutic interventions. Targeting the $\operatorname{PrP}^{\mathrm{C}}$ by inhibiting its synthesis using RNAi or increasing its clearance with anti-PrP antibodies is a valuable strategy for prevention of prion diseases currently being investigated through gene therapy approaches (Daude et al., 2003; Perrier et al., 2004; White et al., 2008). Another approach consists of targeting the pathological $\operatorname{PrP}^{\mathrm{Sc}}$. A fundamental biochemical property that allows differentiation of $\operatorname{PrP}^{\mathrm{Sc}}$ from $\operatorname{PrP}^{\mathrm{C}}$ is the partial resistance of $\mathrm{PrP}^{\mathrm{Sc}}$ to proteinase $\mathrm{K}$ (PK) digestion, leading to a truncated $\mathrm{PrP}^{\mathrm{Sc}}$ form called $\mathrm{PrP}(27-$ 30 ), the main marker of the disease (Fig. 1.1). Many screening assays to identify new anti-prion drugs have focused on reducing the level of $\operatorname{PrP}(27-30)$ (Fig. 1.2). This reduction reflects decreased levels of $\mathrm{PrP}^{\mathrm{Sc}}$ species in the cells, correlated in most cases with diminished infectivity. This strategy led to the identification of many potential anti-prion drugs, but minor benefits were observed in vivo (Ludewigs et al., 2007). Targeting amyloid fibrils was also explored using amyloid dyes (Adjou et al., 1999; Beringue et al., 2000), but in vivo effects were disappointing because of their low ability to cross the blood-brain barrier. Other studies showed that targeting fibrils could result in an unexpected increase in infectivity (Beringue et al., 2000; Rudyk et al., 2000), which was also observed using the protein misfolding cyclic am- 
1: Prion infected sample

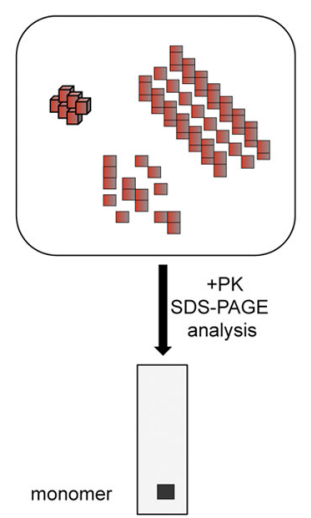

Truncated PrPSc: PrP27-30 marker
2: Screening for anti prion drugs: inhibition of $\operatorname{PrP}(27-30)$ marker

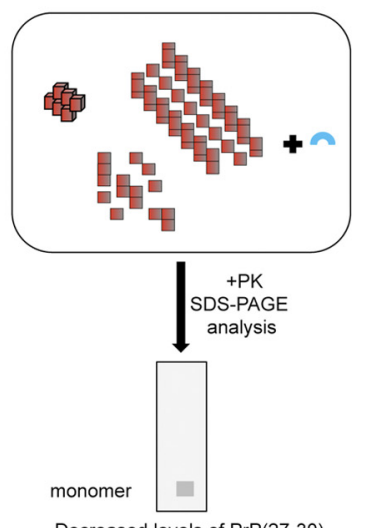

Decreased levels of $\operatorname{PrP}(27-30)$
3: Screening for anti prion drugs promoting multimers of $\operatorname{PrP}(27-30)$ marker via stabilization

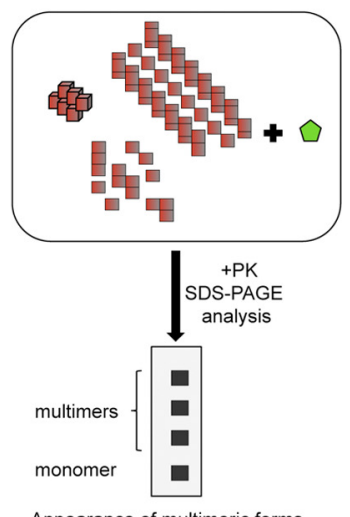

Appearance of multimeric forms
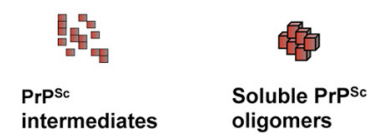

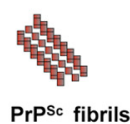

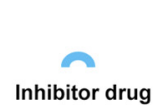

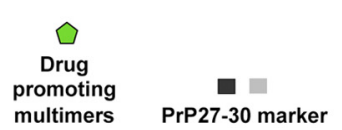

Figure 1. Schema describing classical and new drug-screening assays in prion-infected cells. 1, The infectious agent is present under various forms in prion-infected cells (pre-amyloid intermediates, soluble oligomers of $\mathrm{PrP}{ }^{\mathrm{Sc}}$, proto-fibrils, and amyloid fibrils of $\mathrm{PrP}^{\mathrm{Sc}}$ ). After a proteinase $\mathrm{K}$ digestion step and under SDS and reducing conditions, small and large aggregates of $\mathrm{PrP}^{\mathrm{Sc}}$ undergo fragmentation, leading to a truncated $\operatorname{PrP}(27-30)$ marker. 2, Classical drug-screening assays aim to search for inhibitors of prions exhibiting a decrease in the levels of $\operatorname{PrP}(27-30)$ marker. 3, In our new drug-screening approach, we aimed at identifying drugs able to promote multimer formation through stabilization or cross-linking of $\operatorname{PrP}^{\mathrm{Sc}}$ subunits. Because of stabilization with drugs, multimers of $\operatorname{PrP}(27-30)$ more resistant to denaturation can be detected.

plification (PMCA) technique, when large amyloid aggregates were broken up into smaller ones (Saborio et al., 2001; Wang et al., 2010). Altogether, these works led to the emerging concept that amyloid fibrils, rather than being a pathological entity, might be the result of a protective process to sequester more dangerous soluble oligomers (Caughey and Lansbury, 2003; Silveira et al., 2005; Simoneau et al., 2007).

Regarding this concept, we hypothesize from a therapeutic point of view that it might be better to block or trap amyloid structures rather than to solubilize or break them. Given that, after PK treatment and in SDS and reducing conditions, a complete fragmentation of $\mathrm{PrP}^{\mathrm{Sc}}$ amyloid fibrils and aggregates occurs, leading to the $\operatorname{PrP}(27-30)$ marker, we searched for small molecules interacting with $\operatorname{PrP}^{\mathrm{Sc}}$-promoting $\operatorname{PrP}(27-30)$ oligomers, which would suggest a stabilization or a cross-linking step for those structures (Fig. 1.3). To accomplish this search, we developed a rational drug design approach to identify small molecules interacting with PrP, combined with a drug-screening assay using prion-infected cells. The results pinpointed a family of thienyl pyrimidine derivatives that induce SDS-resistant dimers and trimers of $\operatorname{PrP}(27-30)$. Bioassay experiments showed that these thienyl pyrimidine derivatives diminished prion infectivity in vivo.

\section{Materials and Methods}

Ethics statement. The Comité Régional d'Ethique de Montpellier approved the project (number CE-LR-0702).

Reagents and antibodies. Compounds selected in silico were purchased from Maybridge, Key Organics Limited, and Sigma. Stock solutions were prepared at $5 \mathrm{~mm}$, and drugs were solubilized in DMSO (the solvent control) according to supplier recommendations.

P30 is 4-(5-bromo-2-thienyl)-2-(methylthio)pyrimidine; A6 is 2-(2'thienyl)-5-(4"-(2"-aminopyrimidyl)thiophene); A12 is 4-(5-bromo-2- thie- nyl)-2-pyrimidinamine; A13 is 4-(5-chloro-2thienyl)-2-pyrimidinamine; A14 is $4-(5-$ (thien-2-yl)-thien-2-yl)-2-

mercaptopyrimidine; A16 is 2-(methylthio)4-(3-thienyl)pyrimidine; A17 is 5-(2-(sulfanyl-4pyrimidyl)-2-thiophenecarbonitrile; and A18 is 4-(methylthio)-6-(2-thienyl)-1,3,5-triazin-2amine. Pefabloc and PK were purchased from Roche Diagnostics. Ketamine was obtained from Mérial and xylazine from Bayer HealthCare. The protein assay kit based on bicinchoninic acid (BCA) was purchased from Pierce (Thermo Fisher Scientific). All of the anti-PrP antibodies directed against scrapie associated fibrils (SAF) used in this study were kindly provided by Dr. Jacques Grassi (Commissariat à l'Énergie Atomique et aux Énergies Alternatives, Saclay, France). Secondary antibodies were from Jackson ImmunoResearch. For immunohistology, anti-glial fibrillary acidic protein (GFAP) antibodies were purchased from AbCys, and the secondary antibody was included in the Strept ABC Complex kit (AbCys). All other chemicals were from Sigma.

In silico screening. The structural coordinates of human $\operatorname{PrP}^{\mathrm{C}}\left(\mathrm{HuPrP}^{\mathrm{C}}\right)$ (1QLZ, Protein Data Bank) were used for molecular modeling studies of the PrP and the search for a putative binding site conserved in both $\mathrm{PrP}^{\mathrm{C}}$ and $\mathrm{PrP}^{\mathrm{Sc}}$ isoforms. The in silico screening was performed using the Bioinfo chemical library (Kellenberger et al., 2007) and the Gold 2.0 Software (Jones and Thornton, 1997; Verdonk et al., 2003). Candidate molecules were visualized at the conserved binding site using the Insight II Accelrys software with the Silicon Graphics SGI 02 R10000 workstation.

Cell culture. The mouse neuroblastoma cell line N2a was purchased from the American Type Culture Collection (ATCC CCL131). The N2a58 subclone, which overexpresses mouse $\operatorname{PrP}(\mathrm{MoPrP})$, was chronically infected with the mouse-adapted scrapie strain 22L (N2a58/22L cells), as described by Nishida et al. (2000). N2a58 cells and N2a58/22L cells were grown in Opti-MEM medium with L-glutamine supplemented with $10 \%$ fetal calf serum, $1 \%$ penicillin-streptomycin, and $300 \mu \mathrm{g} / \mathrm{ml}$ geneticin. Cells were split twice per week, with a rotation period of 3-4 d. Cells were maintained at $37^{\circ} \mathrm{C}$ with $5 \% \mathrm{CO}_{2}$.

Cell screening assay and immunoblotting. N2a58/22L cells $\left(\sim 10^{6} / 25\right.$ $\mathrm{cm}^{2}$ flasks) were incubated with various compounds at a final concentration of $20 \mu \mathrm{M}$ (corresponding to $20 \mu \mathrm{l}$ of drug at $5 \mathrm{~mm}$, in $5 \mathrm{ml}$ of medium for T25 plate) for $4 \mathrm{~d}$ as described previously for drug-screening test (Perrier et al., 2004). At confluence, cells were lysed in $400 \mu \mathrm{l}$ of lysis buffer $(0.5 \%$ NP- $40,0.5 \%$ deoxycholate, $10 \mathrm{~mm}$ Tris-HCl, $\mathrm{pH} 8$, and 100 $\mathrm{mm} \mathrm{NaCl}$ ), and protein concentration was measured using the BCA assay. Samples of equal protein amounts and volumes were digested with $20 \mu \mathrm{g} / \mathrm{ml} \mathrm{PK}$ at a ratio of $1: 25$ (protease/protein) at $37^{\circ} \mathrm{C}$ for $1 \mathrm{~h}$. Digestion was stopped with $1 \mathrm{~mm}$ Pefabloc, and samples were centrifuged at $20,000 \times g$ at $4^{\circ} \mathrm{C}$ for $30 \mathrm{~min}$. Pellets were dissolved in $20 \mu \mathrm{l}$ of lysis buffer and $20 \mu \mathrm{l}$ of $2 \times$ loading buffer ( $100 \mathrm{~mm}$ DTT, $3 \%$ SDS, $20 \%$ glycerol, 100 $\mathrm{mm}$ Tris- $\mathrm{HCl}, \mathrm{pH} 6.8$, and bromophenol blue) and then boiled for $3 \mathrm{~min}$ before loading on $12 \%$ SDS-PAGE precast Criterion gels (Bio-Rad). Western blotting was performed according to standard procedures. MoPrP was detected by using a mixture (SAF mix) of three anti-PrP monoclonal antibodies, SAF60, SAF69, and SAF70, as described previously (Perrier et al., 2004).

Dose-response curves. Approximately $10^{6}$ N2a58 or N2a58/22L cells, plated in $25 \mathrm{~cm}^{2}$ flasks, were incubated with P30 or A6 at various concentrations, ranging from 5 to $40 \mu \mathrm{M}$ (corresponding to 5-40 $\mu \mathrm{l}$ of drug at $5 \mathrm{~mm}$, in $5 \mathrm{ml}$ of medium for T25 plate) for $4 \mathrm{~d}$. At confluence, cells were lysed, and the extracts were digested with PK and analyzed by West- 
ern blotting using the SAF mix for N2a58/22L samples as described previously (Nishida et al., 2000) and SAF32 antibodies for N2a58 samples (Perrier et al., 2004) as classically used.

Purification of prion protein. Full-length recombinant mouse PrP encompassing residues 23-230 (MoPrP23-230) was expressed and purified as described previously (Bocharova et al., 2005). The purified recombinant MoPrP23-230 was confirmed by SDS-PAGE and electrospray mass spectrometry to be a single species with an intact disulfide bond and correct molecular weight. After purification, MoPrP23-230 was stored in lyophilized form at $-20^{\circ} \mathrm{C}$ until use.

Binding interaction studies by surface plasmon resonance. Surface plasmon resonance experiments were performed using a BiaCore 3000 (GE Healthcare). Full-length MoPrP23-230 was covalently immobilized on a CM5 sensor chip (GE Healthcare BiaCore AB) by the amine coupling standard procedure. A 4000-5000 RU immobilization level was obtained. For binding measurements $\mathrm{P} 30, \mathrm{~A} 12, \mathrm{~A} 15$, and the positive control quinacrine (Touil et al., 2006) were injected at $40 \mu \mathrm{M}$ in PBS containing 5\% DMSO with a flow rate of $30 \mu \mathrm{l} / \mathrm{min}$ in PrP and blank flow cells. Surfaces were then washed with pulses of $10 \mathrm{~mm} \mathrm{NaOH}$ until complete regeneration. The value (collected at a rate of $2.5 \mathrm{~Hz}$ ) obtained in the reference flow cell were subtracted from those obtained in the PrP flow cell. Buffer blanks were injected before each drug injection, and binding responses were corrected for DMSO bulk differences using calibration curves (eight DMSO solutions between 4.5 and 5.8\% DMSO). For $K_{\mathrm{d}}$ determination, different concentrations of P30 (from 5 to $80 \mu \mathrm{M}$ ) were injected in PBS, 5\% DMSO over the reference and PrP flow cells at a flow rate of $30 \mu \mathrm{l} / \mathrm{min}$ for $60 \mathrm{~s}$. Responses from the injection of drug compounds were extracted $10 \mathrm{~s}$ before the end of the injection. These responses were further corrected for DMSO effects by using the calibration curves, and the final response values were used for plotting the dose-response curve and for $K_{\mathrm{d}}$ determination by steady-state analysis (BiaEvaluation 4.1).

Incubation of MoPrP23-230 fibrils with thienyl pyrimidine compound. Amyloid fibrils using full-length MoPrP23-230 were formed using the manual setup protocol as described previously by Breydo et al. (2008). Fibril formation was monitored by collecting aliquots to which $10 \mu \mathrm{M}$ thioflavine T were added as described previously by Breydo et al. (2008). The quality of freshly made fibrils was also checked by transmission electron microscopy as described previously (El Moustaine et al., 2008). Samples of soluble MoPrP23-230 or fibrils at a final concentration of 4.4 $\mu \mathrm{M}$ were incubated with 5 or $50 \mu \mathrm{M}$ P30 in MES buffer ( 50 mM MES, pH $5.0,1 \% \mathrm{DMSO}$ ) at $25^{\circ} \mathrm{C}$ for $2 \mathrm{~h}$. Ten microliters of each sample were mixed with the appropriate loading buffer (according to the protocols described previously), boiled at $90^{\circ} \mathrm{C}$ for $10 \mathrm{~min}$ before loading onto $12 \%$ SDS-PAGE gels. Silver staining was used to reveal the proteins in the gel (Chevallet et al., 2006).

Conversion of full-length MoPrP23-230 into amyloid fibrils in the presence of thienyl pyrimidine compounds using a semi-automated assay. The conversion of MoPrP23-230 into amyloid fibrils in a semi-automated setup was performed in fourfold to ensure reproducibility, according to a protocol described previously (Breydo et al., 2008). The following reagents were mixed in conical plastic tubes: $2 \mathrm{M} \mathrm{GdnHCl,} 50 \mathrm{~mm}$ MES buffer, $\mathrm{pH}$ 6.0, $10 \mu \mathrm{M}$ thioflavine T, $10 \mathrm{~mm}$ thiourea, $30 \mu \mathrm{g} / \mathrm{ml} \operatorname{PrP}$ in $6 \mathrm{M}$ $\mathrm{GdnHCl}$, and $40 \mu \mathrm{M}$ P30 drug, in a final volume of $500 \mu$ l. After thorough mixing, the reaction mixture was aliquoted into four wells of a 96-well plate that was sealed. Plates were incubated at $37^{\circ} \mathrm{C}$ with shaking at 900 rpm (shaking diameter, $1 \mathrm{~mm}$ ), and fluorescence was measured every 5 or 10 min with excitation at $444 \mathrm{~nm}$ and emission at $485 \mathrm{~nm}$.

Kinetics of $\operatorname{PrP}(27-30)$ dimer and trimer in the presence of $P 30$ and A6. N2a58/22L cells were incubated with $20 \mu \mathrm{M}$ P30 or A6, or $20 \mu \mathrm{l}$ of DMSO as control for the solvent alone. After 3-4 d, confluent cells were divided into duplicate flasks, one used for Western blot analysis and the other for prolongation of the treatment with drugs for a total of $11 \mathrm{~d}$. At the end of the treatment, cells were grown without drugs for 10 additional days. Then cells were lysed, and cell extracts were treated with PK and analyzed by Western blotting, as described previously (Nishida et al., 2000).

Conformational stability assay. N2a58/22L cells were incubated with 20 $\mu \mathrm{M}$ P30 or A6, or $20 \mu \mathrm{l}$ of DMSO as control for the solvent alone for $4 \mathrm{~d}$. At confluence, cells were lysed with $200 \mu$ l of lysis buffer. Each sample was normalized for equal protein amounts. Cellular extracts were incubated with $50 \mu \mathrm{l}$ of $\mathrm{GdnHCl} \mathrm{mix}$, at a final concentration ranging from 0 to $1.5 \mathrm{M}$, for $2 \mathrm{~h}$ at room temperature. Then samples were diluted by addition of $750 \mu \mathrm{l}$ of lysis buffer and digested with PK $(8 \mu \mathrm{g} / \mathrm{ml})$ at $37^{\circ} \mathrm{C}$ for $1 \mathrm{~h}$. Reactions were stopped by addition of $1 \mathrm{~mm}$ Pefabloc and subsequently centrifuged at $20,000 \times g$ at $15^{\circ} \mathrm{C}$. Pellets were dissolved in $20 \mu \mathrm{l}$ of lysis buffer and $20 \mu \mathrm{l}$ of $2 \times$ loading buffer. Western blotting was performed as described above.

Aggregation assays on cell lysates and brain homogenates. Fresh N2a58/ 22L cell extracts prepared in $400 \mu \mathrm{l}$ of lysis buffer were incubated with various concentrations of P30 (from 12.5 to $625 \mu \mathrm{M}$, corresponding to 1 to $50 \mu \mathrm{l}$ of $\mathrm{P} 30$ at $5 \mathrm{~mm}$ ) at $20^{\circ} \mathrm{C}$ for $1 \mathrm{~h}$. Because cell lysates were incubated with the drug for only $1 \mathrm{~h}$ compared with $3 \mathrm{~d}$ of cellular screening assays, it was important to concentrate the reaction volume to promote interactions while keeping the same drugs/proteins ratio. Then samples were digested with PK and analyzed by Western blotting according to the protocol described above.

Brain tissues from terminally sick mice inoculated with the scrapie strain 22L were homogenized in $10 \%$ (w/v) PBS using microbeadcontaining tubes and a Ribolyser apparatus (Bio-Rad). Samples were shaken for $45 \mathrm{~s}$, and then supernatants were passed through an insulin syringe to obtain a homogeneous suspension. Protein amounts were measured using the BCA assay. To show the oligomeric activity of P30 in brain homogenates, we incubated different quantities of 22L-infected brain extracts $(50-75 \mu \mathrm{l})$, diluted in PBS with $2 \%$ Sarkosyl, with $0.5-3$ $\mathrm{mm}$ P30 (corresponding to $50-300 \mu \mathrm{l}$ of drug at $5 \mathrm{~mm}$ stock solution) or $200 \mu \mathrm{l}$ of DMSO as a solvent control, in a final volume of $0.5 \mathrm{ml}$ for 1-3 h. Samples were then digested with $20 \mu \mathrm{g} / \mathrm{ml} \mathrm{PK}$ as described previously (Perrier et al., 2002). Fifty microliters of each sample were mixed with an equal volume of $2 \times$ loading buffer and boiled for $3 \mathrm{~min}$. Thirty microliters were loaded onto $12 \%$ SDS-PAGE gels and analyzed by Western blotting.

Then we incubated 22L brain homogenate with $1.5 \mathrm{~mm}$ P30 or A6 during $1 \mathrm{~h}$ at room temperature, and samples were proteinase $\mathrm{K}$ digested and fractionated with loading buffer (containing SDS and DTT). Samples were loaded on non-denaturing gel (Criterion Precast Tris-HCl; Bio-Rad) and transferred on to PVDF membrane using a Tris-glycine buffer (Bio-Rad). Membrane was revealed with SAF mix antibodies as described previously.

Evaluation of proteinase $K$ resistance. Twenty-five microliters of 22L-infected brain extract were incubated with $1.5 \mathrm{~mm} \mathrm{P30} \mathrm{or} 75 \mu \mathrm{l}$ of DMSO in a final volume of $0.25 \mathrm{ml}$ for $1 \mathrm{~h}$ at room temperature. Then PK was added to a final concentration ranging from 0.1 to $1.2 \mathrm{mg} / \mathrm{ml}$ for $1 \mathrm{~h}$ at $37^{\circ} \mathrm{C}$. Reactions were stopped by addition of $1 \mathrm{~mm}$ Pefabloc. Fifty microliters of each sample were mixed with an equal volume of $2 \times$ loading buffer and boiled for $3 \mathrm{~min}$. Thirty microliters were loaded onto $12 \%$ SDS-PAGE gels and analyzed by Western blotting as described previously.

Bioassay using N2a58/22L cells. After $38 \mathrm{~d}$ of treatment with $20 \mu \mathrm{M}$ P30 or $20 \mu \mathrm{l}$ of DMSO, confluent cells (100 mm plate) were washed twice with $5 \mathrm{ml}$ PBS and scraped with $0.5 \mathrm{ml}$ PBS. Cells were broken through four cycles of freezing and thawing and homogenized by repeated extrusion through a 26-gauge needle. Prion infectivity was determined by intracerebral inoculation of $15 \mu \mathrm{l}$ of cell homogenate (diluted $10^{3}$ with normal cell extract) in female Swiss mice (Janvier) using a stereotaxic frame (David Kopf Instruments) with coordinates as follows, using Bregma as a reference: lateral, $1.0 \mathrm{~mm}$; anteroposterior, $-1.0 \mathrm{~mm}$; and ventral, $-3.0 \mathrm{~mm}$ (Paxinos and Franklin, 1997). Three groups of five mice were housed in cages placed in a ventilated protective cabinet, but two mice died from intercurrent disease in DMSO and P30 groups $(n=$ 13). All experiments were performed in a biosafety level 3 laboratory, according to the local ethical committee's guidelines. Mice were scored positive for prion disease when three signs of neurologic dysfunction were observed and when progressive deterioration of the animal was apparent according to 16 diagnostic criteria, as described previously (Carlson et al., 1986; Scott et al., 1989). Once clinical signs were detected, animals were killed in extremis. Their brains were removed and either immediately frozen at $-80^{\circ} \mathrm{C}$ or fixed in AntigenFix (Diapath) for immunohistochemical analysis. 
Bioassay using 22L-infected brain homogenates. To determine the infectivity of $\mathrm{P} 30$-induced $\mathrm{PrP}^{\mathrm{Sc}}$ oligomers in mouse brain homogenates, we incubated $50 \mu \mathrm{l}$ of $10 \%(\mathrm{w} / \mathrm{v}) 22 \mathrm{~L}$-infected brain homogenates in PBS, $2 \%$ Sarkosyl $(300 \mu \mathrm{l})$ with P30 at a final concentration of $1.5 \mathrm{~mm}(150 \mu \mathrm{l})$, or $150 \mu \mathrm{l}$ of DMSO as a control, at $20^{\circ} \mathrm{C}$ for $2 \mathrm{~h}$. Samples were then diluted $10^{3}$ times with normal brain homogenates before inoculation into animals. Prion infectivity was determined by intracerebral inoculation of $15 \mu$ l of the P30-treated samples into female Swiss mice $(n=19)$, using a stereotaxic frame as described in the previous section. At the terminal stage of the disease, animals were killed, and their brains removed as described above.

Immunohistochemistry. Brain tissues were fixed in AntigenFix solution (Diapath) for $24 \mathrm{~h}$. Then they were decontaminated for $30 \mathrm{~min}$ in a formic acid solution according to the protocol described by Andréoletti (2004) and stored in $100 \mathrm{~mm}$ phosphate buffer at pH 7.4 with $0.02 \%$ sodium azide. Samples were dehydrated in graded ethanol, cleared in cedar oil, and then embedded in paraffin. Frontal $6-10 \mu \mathrm{m}$ sections were cut using a microtome and mounted on Superfrost Plus slides (Microm). Sections were dewaxed and stained with hematoxylin and eosin. Immunolabeling with anti-GFAP antibodies was performed according to the instructions provided with the Strept ABC Complex kit. Labeling was visualized using 3-3'-diaminobenzidine chromogen solution (Sigma).

Software and statistical analysis. Survival curves were done using GraphPad Software. We used R software version 2.9.0. for statistical analysis. The nonparametric Wilcoxon's test with a probability of 0.05 defined as a significant difference was applied for comparison of mice injected with 22L-infected brain homogenates treated with P30 versus the group inoculated with $22 \mathrm{~L}$-infected brain homogenates treated with DMSO only.

\section{Results}

\section{Selection of compounds that interact with PrP using a} structure-based drug design approach

We developed a rational drug design approach to identify chemical molecules that could interact with $\mathrm{PrP}^{\mathrm{Sc}}$ species. Crystal structure studies have revealed that, in the case of globular proteins, small molecules act directly through the plasticity of the interface or allosterically by inducing conformational changes at distant sites (Arkin and Wells, 2004); thus, we first determined by molecular modeling whether we could identify a structurally conserved region at the surfaces of both $\mathrm{PrP}^{\mathrm{C}}$ and $\mathrm{PrP}^{\mathrm{Sc}}$ that could serve as a putative binding site. According to structural studies on the scrapie PrP by Wille et al. $(2002,2009)$, theoretical and experimental evidence indicates that the $\mathrm{B}$ and $\mathrm{C}$ helices in $\mathrm{PrP}^{\mathrm{C}}$ are also conserved in $\mathrm{PrP}^{\mathrm{Sc}}$. Because these segments are joined by a disulfide bridge (C179-C214) that is also retained in $\mathrm{PrP}^{\mathrm{Sc}}$ and required for infectivity, we focused our studies around these two conserved structural helices in the vicinity of the disulfide bridge. Moreover, Wille and colleagues (Wille et al., 2002; Colby et al., 2009) showed that the $\alpha$ helices of $\operatorname{PrP}^{\mathrm{Sc}}$ are located toward the outside of the oligomers, which would be expected to facilitate the docking of a small molecule.

Our molecular modeling of this region in $\mathrm{HuPrP}^{\mathrm{C}}$ (1QLZ, Protein Data Bank) revealed the existence of a putative binding site that encompasses residues Y162-C179 and C214-S222 as well as the disulfide bridge at the end of the tiny binding pocket (Fig. 2A). From the Bioinfo chemical library, we then selected a first group of 350,000 small aromatic and bicyclic molecules with a polar surface smaller than $100 \AA$ that could cross the bloodbrain barrier. We then screened in silico for ligands of these compounds using Gold 2.0 software with a $15 \AA$ radius sphere located at the center of the disulfide bridge of $\mathrm{HuPrP}^{\mathrm{C}}$ as the putative binding site. We retained only molecules with a binding score higher than 50 within a scale going up to 100 . We visualized 37 molecules with the best scores at the putative binding site, and, among these, 32 were available for purchase.
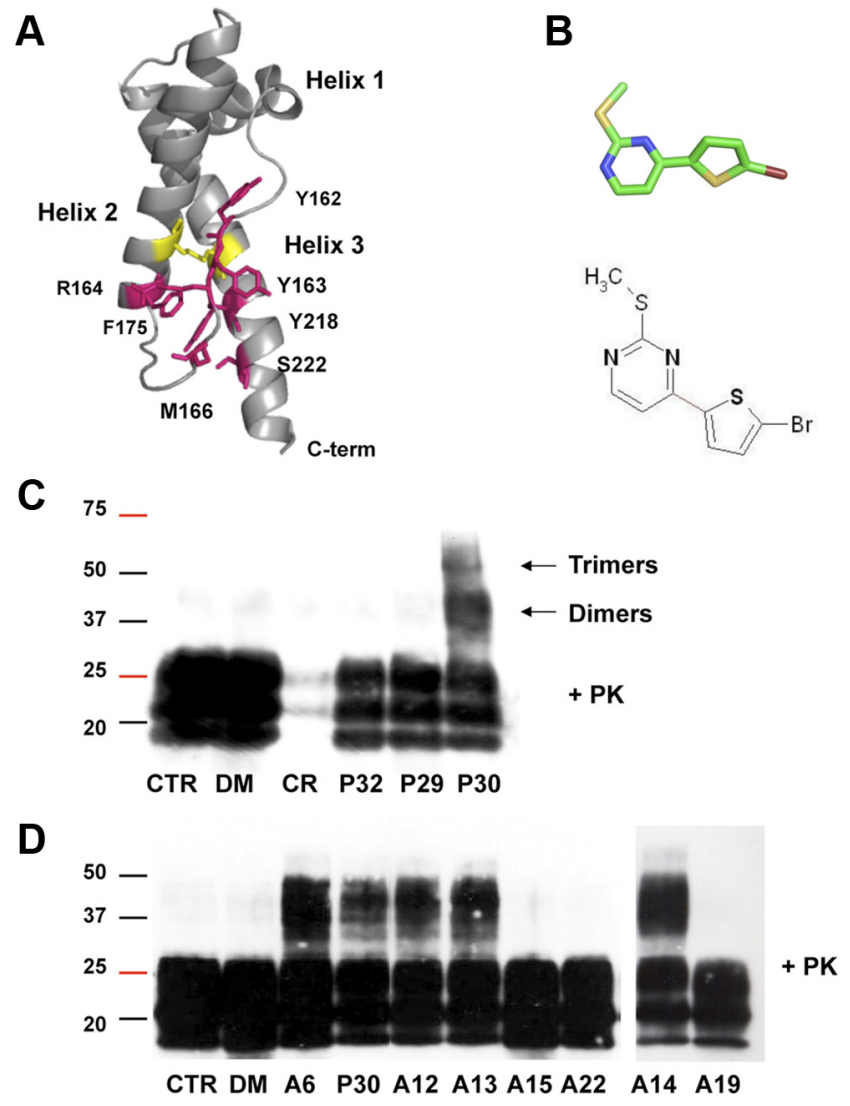

Figure 2. Identification of P30 by a structure-based drug design strategy, followed by cellular screening. $\boldsymbol{A}$, Identification of a putative binding site on the HuPrP protein (10LZ, Protein Data Bank) spanning along residues Y162-C179 (including the residue F175-C179 of $\alpha$-helix 2) and (214-\$222 ( $\alpha$-helix 3) and the disulfide bridge at the end of the tiny binding pocket. The disulfide bridge (in yellow) and the side chains of amino acid residues Tyr163, Arg164, Met166, Phe175, and Tyr 218 (in purple) define the putative binding site for the small molecules selected in silico. The image was created by using PyMol software (www.pymol.org). B, Depiction of P30. C, Screening of small molecules selected in silico in prion-infected N2a58/22L cells. N2a58/22L cells were incubated with $20 \mu \mathrm{m}$ of the 32 compounds selected by virtual screening for $4 \mathrm{~d}$. Then protein lysates were digested with $20 \mu \mathrm{g} / \mathrm{ml}$ proteinase $\mathrm{K}(+\mathrm{PK})$, and PrP $\mathrm{sc}$ accumulation was analyzed by immunoblotting (see Materials and Methods for more details) with the SAF mix (a mixture of SAF60, SAF69, and SAF70, three anti-PrP monoclonal antibodies). CTR, Negative control, untreated prion-infected N2a58/22L cells; DM, cells incubated with $20 \mu \mathrm{l}$ of DMSO alone; CR, cells incubated with $20 \mu \mathrm{m}$ Congo Red as a positive control for inhibition of PrP ${ }^{\mathrm{Sc}}$ accumulation. Among the 32 drugs tested (see Notes), only P30 triggered oligomerization of $\operatorname{PrP}(27-30)$ into dimers and trimers (see arrows). Molecular masses (15-75 $\mathrm{kDa}$ ) are indicated on the left of the panel. $\boldsymbol{D}$, Cellular screening of 23 derivatives of the P30 compound. Prion-infected N2a58/22L cells were incubated with $20 \mu \mathrm{m}$ of the 23 compounds, selected for their structural analogies with P30, for $4 \mathrm{~d}$ and lysates processed as mentioned above. PrP ${ }^{\mathrm{Sc}}$ accumulation was analyzed by immunoblotting with the SAF mix. A6, A12, A13, $A 14, A 15, A 19$, and $A 22$ (see Materials and Methods for full names) were drug tested (see also Table 1).

\section{Cellular screening of compounds selected in silico}

We then tested whether the 32 compounds identified by our computational screening could block or promote $\operatorname{PrP}^{\mathrm{Sc}}$ aggregates in prion-infected cells. Technically, control samples were submitted to a PK digestion step and to SDS denaturing and reducing conditions, including a boiling step at $100^{\circ} \mathrm{C}$, leading to dissociation of the $\mathrm{PrP}^{\mathrm{Sc}}$ aggregates in one main form of the $\operatorname{PrP}(27-30)$ marker visible on Western blot. A stabilization of $\mathrm{PrP}^{\mathrm{Sc}}$ aggregates, for instance, by cross-linking $\operatorname{PrP}^{\mathrm{Sc}}$ subunits with small molecules could lead under denaturing and reducing conditions to the detection of small oligomers of $\operatorname{PrP}(27-30)$. Our cellular test was to search for compounds with this ability. To 
Table 1. Structure of P30 analogues and their PrP oligomerization activity assessed in cells at $20 \mu \mathrm{M}$

\begin{tabular}{|c|c|c|c|c|c|}
\hline Compound & Structure & $\begin{array}{c}\operatorname{PrP} \\
\text { oligomerization }\end{array}$ & Compound & Structure & $\begin{array}{c}\text { PrP } \\
\text { oligomerization }\end{array}$ \\
\hline A 1 & & - & A 13 & & ++ \\
\hline $\mathrm{A} 2$ & & - & A 14 & & +++ \\
\hline A3 & & - & A 15 & & - \\
\hline A4 & & - & A 16 & & + \\
\hline A5 & & - & A 17 & & + \\
\hline A6 & & +++ & $\mathrm{A} 18^{\mathrm{a}}$ & & + \\
\hline A7 & & - & A19 & & - \\
\hline A8 & & - & A 20 & & - \\
\hline A9 & & - & A 21 & & - \\
\hline A 10 & & - & A22 & & - \\
\hline A11 & & - & A 23 & & - \\
\hline A 12 & & ++ & & & \\
\hline
\end{tabular}

${ }^{a}$ oligomeric activity detected with A18 at $40 \mu \mathrm{M}$ 
A

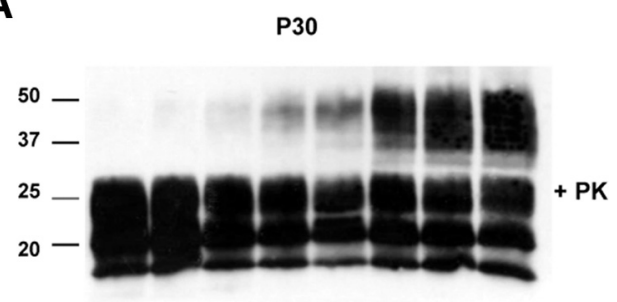

B

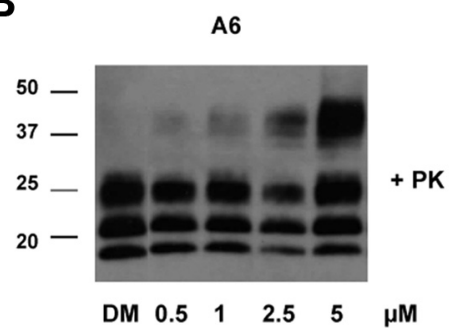

Figure 3. Oligomerization of $\mathrm{PrP}^{\mathrm{Sc}}$ in prion-infected cells treated with $\mathrm{P} 30$ and $\mathrm{A} 6$ is dose dependent. $A$, Prion-infected N2a58/22L cells were incubated with 5- $40 \mu \mathrm{m}$ P30 (corresponding to 5-40 $\mu$ l of drug at $5 \mathrm{~mm}$ ), $40 \mu$ l of DMSO (DM), or left untreated (CTR) for $4 \mathrm{~d}$. Protein lysates were analyzed by immunoblotting after proteinase $\mathrm{K}$ digestion. $\boldsymbol{B}$, Similarly, prioninfected N2a58/22L cells were incubated with 5-20 $\mu \mathrm{m} \mathrm{A6}$ or $20 \mu$ lof DMSO (DM) as a control, for $4 \mathrm{~d}$. Protein lysates were then analyzed by immunoblotting after proteinase $\mathrm{K}$ digestion. Molecular masses $(15-50 \mathrm{kDa})$ are indicated on the left of the panels. Immunoblots were revealed with the SAF mix.

this aim, N2a58/22L cells were incubated with $20 \mu \mathrm{M}$ of each of the 32 compounds for $4 \mathrm{~d}$. At that time, cells reached confluence and were lysed. Negative controls were untreated N2a58/22L cells (controls) or incubated with $20 \mu \mathrm{l}$ DMSO (solvent control). Crude extracts were analyzed by immunoblotting after PK digestion. Only one compound, $\mathrm{P} 30$, increased $\mathrm{PrP}(27-30)$ oligomerization, especially dimer $(\sim 50 \mathrm{kDa})$ and trimer $(\sim 75 \mathrm{kDa})$ formation (Fig. $2 B, C$ ). None of the 32 compounds had an inhibitory effect on $\operatorname{PrP}^{\mathrm{Sc}}$ accumulation, as observed when cells were incubated with $20 \mu \mathrm{M}$ Congo Red.

We then used the thienyl pyrimidine scaffold of P30 to search for P30 analogs displaying the same oligomeric activity. We screened the Bioinfo chemical library again and the ZINC database (http://zinc.docking.org) and found 23 P30 derivatives (Table 1). We then performed a second cell screening in N2a58/22L cells using the same conditions as before. Among the 23 P30 derivatives, six compounds (A6, A12, A13, A14, A16, and A17) induced $\mathrm{PrP}^{\mathrm{Sc}}$ oligomerization as efficiently as $\mathrm{P} 30$ (Table 1, Fig. $2 D)$. To further characterize the properties of this new family of compounds, we focused on two, P30 and A6. To confirm the reproducibility of their oligomeric activity and to see whether this property was dose dependent, N2a58/22L cells were incubated with various concentrations of $\mathrm{P} 30$ and A6, from 5 to $40 \mu \mathrm{M}$, for $4 \mathrm{~d}$. With both compounds, $\operatorname{PrP}^{\mathrm{Sc}}$ oligomerization was reproducible and dose dependent (Fig. $3 A, B$ ).

The effective dose $\mathrm{ED}_{50}$ (concentration at which $50 \%$ of $\mathrm{PrP}^{\mathrm{Sc}}$ oligomerization was achieved) was estimated to be $17 \mu \mathrm{M}$ for P30 and $\sim 2.5 \mu \mathrm{M}$ for A6, indicating a more potent effect of this compound. Finally, the toxicity of P30 and A6 (at $40 \mu \mathrm{M}$ ) in N2a58/ 22L cells was assessed by evaluating cell viability with Trypan Blue. We observed no difference in cell viability between P30and A6-treated cells and control cells incubated with DMSO (data not shown).
A
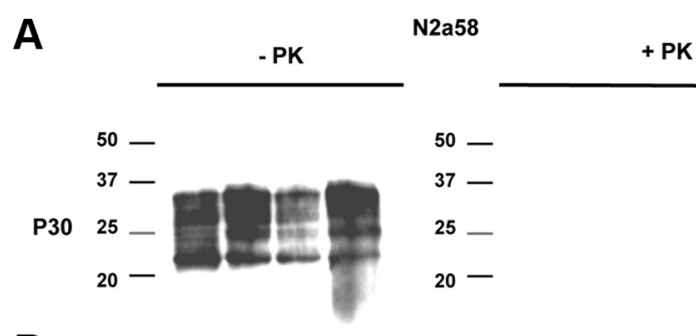

B
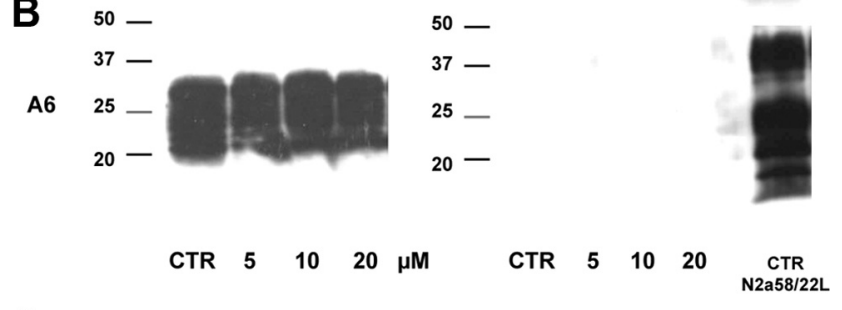

C

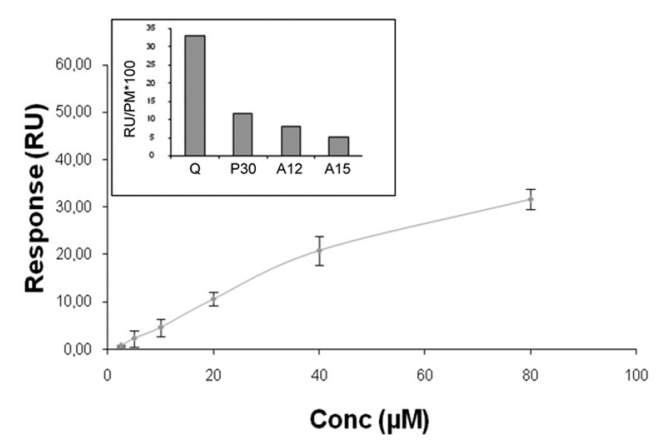

Figure 4. Thienyl pyrimidine compounds do not oligomerize the normal $\operatorname{PrP}^{C}$ isoform. $\boldsymbol{A}$, N2a58 cells were incubated with 5-20 $\mu \mathrm{M}$ P30, or not (CTR), for $4 \mathrm{~d}$. Protein lysates were analyzed by immunoblotting before ( $-\mathrm{PK}$ ) or after (+PK) proteinase K digestion. $\boldsymbol{B}, \mathrm{N} 2 \mathrm{a} 58$ cells were incubated with 5-20 $\mu \mathrm{m}$ A6 for $4 \mathrm{~d}$ and processed as in $\boldsymbol{A}$. Immunoblots were probed with the monoclonal antibody SAF32. Molecular masses $(20-50 \mathrm{kDa})$ are indicated on the left of the panels. $\boldsymbol{C}$, Interaction of soluble MoPrP23-230 with thienyl pyrimidine compounds by surface plasmon resonance. In the inset, a histogram showing the interactions of $\mathrm{P} 30, \mathrm{~A} 12, \mathrm{~A} 15$, and quinacrine ( $Q$ ) drugs at a concentration of $40 \mu \mathrm{m}$, with the MoPrP23-230 immobilized on the sensor chip ( $4000-5000 \mathrm{RU})$. The dose-response curve illustrates the interaction between P30 drug (5-80 $\mu \mathrm{m})$ and the MoPrP23-230 immobilized on the sensor chip (4000-5000 RU).

\section{Thienyl pyrimidine compounds exhibit oligomeric activity} only in prion-infected cells

We then wanted to determine whether the oligomeric-induced activity of $\mathrm{P} 30$ and $\mathrm{A} 6$ was specific for $\mathrm{PrP}^{\mathrm{C}}$, $\mathrm{PrP}^{\mathrm{Sc}}$, or both isoforms. To this aim, N2a58 cells, which overexpress normal PrP, were incubated with various concentrations of P30 or A6 (from 5 to $20 \mu \mathrm{M}$ ) for $4 \mathrm{~d}$. Cell extracts nontreated by PK did not show oligomeric bands using SAF32 antibodies (Fig. 4A). After PK digestion of the P30/A6-treated N2a58 cell extracts, PK-resistant $\mathrm{PrP}^{\mathrm{C}}$ forms were not detected (Fig. $4 \mathrm{~B}$ ). These experiments were also done using different antibodies (SAF mix), and the results were the same. Altogether, these data suggest that P30 and A6 do not allow formation of $\mathrm{PrP}^{\mathrm{C}}$ oligomers resistant to SDS and reducing agent. We then asked whether this specificity for $\operatorname{PrP}^{\mathrm{Sc}}$ could result from the fact that $\mathrm{P} 30$ and $\mathrm{A} 6$ do not bind to $\operatorname{PrP}^{\mathrm{C}}$, although the putative binding site is in a region that is conserved in both isoforms. To this aim, we used surface plasmon resonance (BiaCore) to assess whether P30, A12, and A15 could bind to immobilized MoPrP23-230 (Fig. 4C). Analysis of the results suggested that thienyl pyrimidine compounds could interact with $\operatorname{PrP}^{\mathrm{C}}$, albeit with less affinity than quinacrine (positive control). The calculated affinity for P30 was $K_{\mathrm{d}}=147 \pm 50 \mu \mathrm{M}$. Unfortunately, we could not evaluate their binding to $\operatorname{PrP}^{\mathrm{Sc}}$ because of problems with aggregation of $\mathrm{PrP}^{\mathrm{Sc}}$ to the BiaCore sensor chip. 
Then we asked whether P30 could cross-link recombinant PrP fibrils to form SDS-resistant dimers/trimers. We thus incubated in vitro recombinant mouse PrP fibrils with 5 or $50 \mu \mathrm{MP} 30$ for $2 \mathrm{~h}$ and then evaluated dimer/trimer formation by SDS-PAGE (Fig. $5 A$ ). The absence of dimer/trimer formation suggested that P30 does not cross-link recombinant PrP fibrils. In addition, the analysis of the kinetics of recombinant mouse PrP conversion into amyloid fibrils in the presence of P30 showed that this compound did not have any effect on the kinetics of formation of recombinant amyloid fibrils (Fig. 5B).

\section{$\operatorname{PrP}^{\mathrm{Sc}}$ oligomers are stable after the suppression of treatment with P30 or A6}

We then assessed whether prolonged incubation of N2a58/22L cells with thienyl pyrimidine compounds could increase $\operatorname{PrP}(27-$ 30) dimer and trimer formation at the expense of monomers. N2a58/22L cells were incubated with $20 \mu \mathrm{M}$ P30, A6, or DMSO for $11 \mathrm{~d}$. Assessment of oligomer formation at days 4, 7, and 11 showed no significant difference in the amount of dimers and trimers formed in cells incubated with A6 and P30; however, in protein extracts from cells treated with $\mathrm{P} 30$, less monomeric $\operatorname{PrP}(27-30)$ was accumulated and more trimers were detected compared with A6-treated cells (Fig. 6A).

After $11 \mathrm{~d}$ of treatment, cells were kept in culture without drugs for another $10 \mathrm{~d}$ (time points at days 14, 18, and 21). At day 14, $\operatorname{PrP}(27-30)$ dimers were still detected in extracts of P30-treated and especially A6-treated cells, in which trimers were also visible (Fig. 6A). However, by day 21 , the balance tipped to the benefit of monomer formation despite the persistence of dimers. These results indicated that oligomers persist in the cells, even after the end of treatment, suggesting that these entities are quite stable. To evaluate the conformational stability possibly induced by thienyl pyrimidine compounds, prioninfected cells were first treated with $20 \mu \mathrm{M}$ A6 for $4 \mathrm{~d}$. Then cellular lysates were denatured with guanidine hydrochloride $(0.5-1.5 \mathrm{M})$ to assess conformational stability, followed by a PK digestion step. Up to $1.25 \mathrm{M} \mathrm{GdnHCl}, \operatorname{PrP}(27-30)$ dimers exhibited a conformational stability equivalent to those of monomers of $\operatorname{PrP}(27-30)$. Both DMSO- and A6-treated samples were equivalently denatured by exposure to $1.5 \mathrm{M} \mathrm{GdnHCl}$ (Fig. $6 B$ ).

\section{P30 traps prion infectivity in N2a58/22L cells}

We asked whether this oligomeric activity induced by thienyl pyrimidine drugs could diminish prion infectivity. Thus, N2a58/ $22 \mathrm{~L}$ cells were supplemented with $20 \mu \mathrm{M}$ P30 or $20 \mu \mathrm{l}$ of DMSO for $38 \mathrm{~d}$ (Supattapone et al., 1999). Western blot analysis showed that oligomeric activity was still strong after $34 \mathrm{~d}$ of treatment (Fig. 7A). Then homogenates of P30- or DMSO-treated N2a58/ 22L cells were inoculated into the brains of Swiss mice. All inoculation experiments were performed using a stereotaxic frame to obtain accurate and reproducible injected volumes and sites of injections, because these variables can cause variations in incubation time (Kim et al., 1987). Mice inoculated with P30-treated cell
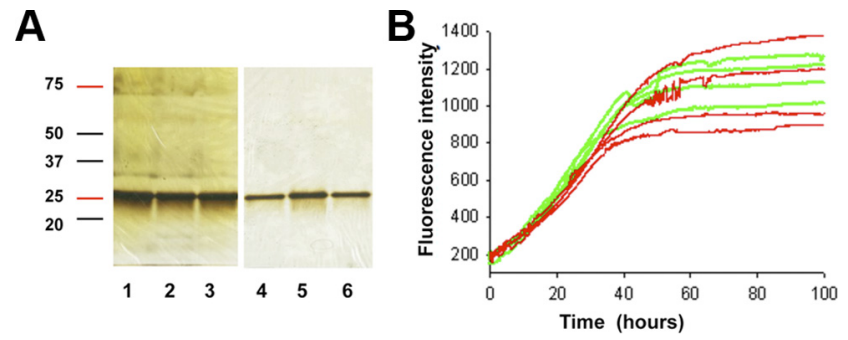

Figure 5. A, P30 does not cross-link full-length MoPrP23-230 or recombinant fibrils. MoPrP23-230 was solubilized in $50 \mathrm{~mm}$ MES buffer, $\mathrm{pH} 5.0,1 \% \mathrm{DMSO}$ and incubated during $2 \mathrm{~h}$ at $25^{\circ} \mathrm{C}$, either without drug (lane 1) or 5 or $50 \mu \mathrm{m} \mathrm{P30} \mathrm{drug} \mathrm{(lanes} 2$ and 3, respectively). Already formed MoPrP fibrils by a manual process were incubated during $2 \mathrm{~h}$ at $25^{\circ} \mathrm{C}$ either without drug (lane 4) or 5 or $50 \mu \mathrm{m}$ P30 drug (lanes 5 and 6, respectively). B, P30 does not modify the kinetics of conversion of MoPrP23-230 into amyloid fibrils. The kinetic of conversion of MoPrP23-230 into amyloid fibrils in a semi-automated setup was performed in presence of $40 \mu \mathrm{M} P 30$ drug (red curves) or DMSO alone (green curves) at $37^{\circ} \mathrm{C}$.

Figure 6. A, Oligomerization of $\operatorname{Pr} P(27-30)$ by thienyl pyrimidine compounds persists after suppression of treatment. PrionN2a58/22L cells were incubated (+) with $20 \mu \mathrm{m}$ P30 or A6 or $20 \mu \mathrm{l}$ of DMSO alone as control for the solvent for $11 \mathrm{~d}$ (time

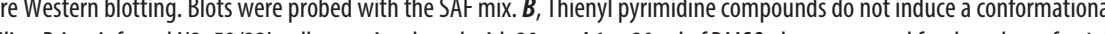
At confluence, cells were lysed and treated with a final concentration of GdnHCl: $0,0.5,0.75,1.0,1.25$, or 1.5 M. Samples were digested with proteinase $K$ before Western blotting. Blots were probed with the SAF mix.
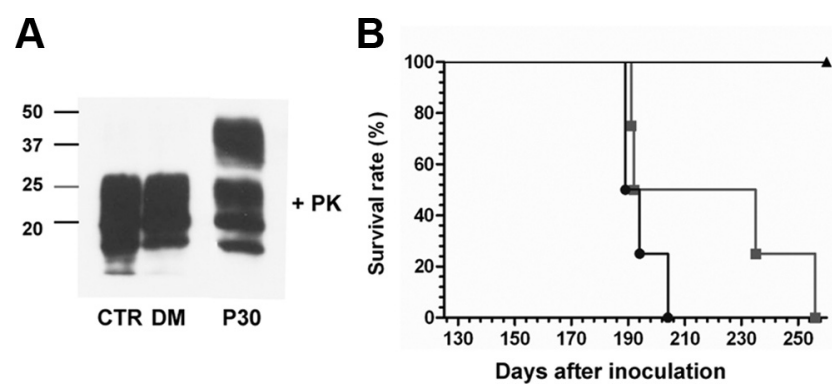

Figure 7. Decrease in prion infectivity in prion-infected N2a58/22L cells treated with P30 Prion-infected N2a58/22 L cells were treated in duplicate with $20 \mu \mathrm{M}$ P30, $20 \mu \mathrm{l}$ of DMSO (DM), or untreated (CTR) for $38 \mathrm{~d}$. $\boldsymbol{A}$, Samples were analyzed by immunoblotting, as described in Figure 2, to check for $\operatorname{PrP}(27-30)$ oligomerization before injection into brains of healthy Swiss mice. $\boldsymbol{B}$, Kaplan-Meier survival plots of Swiss mice inoculated with cell homogenates prepared from prion-infected N2a58/22L cells treated with P30 $(n=4)$ (squares) or DMSO $(n=4)$ (circles). Swiss mice were inoculated with PBS (triangles). 


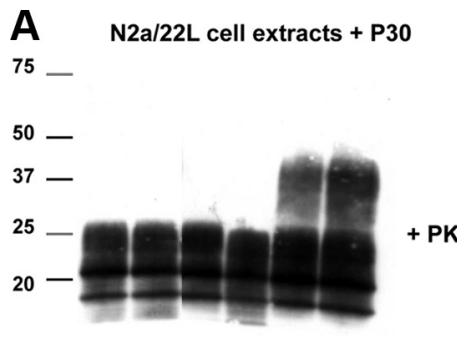

$\begin{array}{lllllll}\text { CTR } & \text { DM } & 12 & 62 & 312 & 625 & \mu M\end{array}$

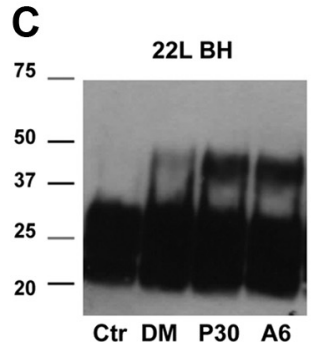

B

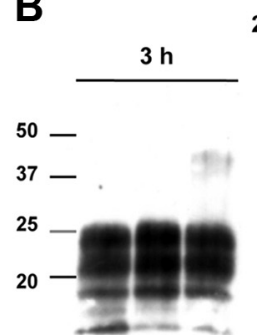

CTR DM 0.5
22L BH + P30

$2 \mathrm{~h}$

CTR 1
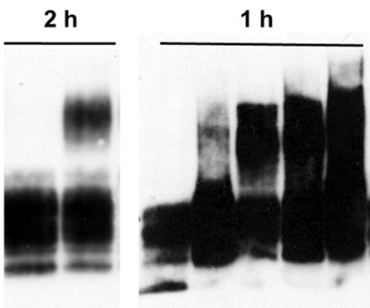

CTR DM $1223 \quad \mathrm{mM}$

D

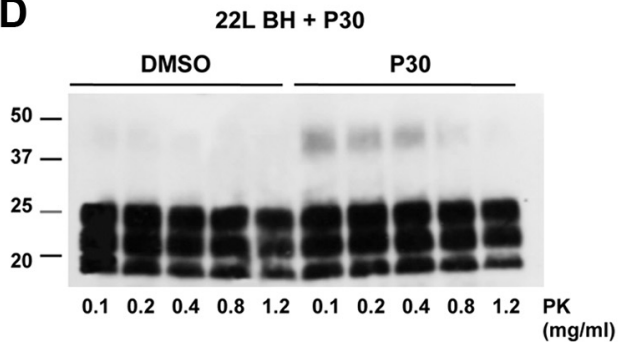

Figure 8. A, P30 induces oligomerization of $\operatorname{PrP}(27-30)$ directly into prion-infected cell lysates. A total of $400 \mu$ l of fresh cell lysates from prion-infected $\mathrm{N} 2 \mathrm{a} 58 / 22 \mathrm{~L}$ cells (each containing equivalent amounts of proteins) was incubated with various quantities of P30 (from 12.5 to $625 \mu \mathrm{m}$, corresponding to 1 to $50 \mu$ lof P30 at $5 \mathrm{~mm}$ ) or $50 \mu$ l of DMSO (DM) at room temperature for $1 \mathrm{~h}$. Then samples were digested by proteinase $\mathrm{K}$ before analysis by Western blotting and probed with the SAF mix. CTR, Negative control, untreated N2a58/22 L cell lysate. B, P30 oligomeric activity is attributable to direct aggregation in prion-infected brain homogenates. The experimental parameters leading to oligomerization of $\mathrm{PrP}^{\mathrm{Sc}}$ in prion-infected brain homogenates were investigated: (i) $75 \mu \mathrm{l}$ of $1 \%$ mouse brain homogenate infected with the 22L scrapie strain diluted in PBS with 2\% Sarkosyl (22Linfected brain homogenate) was incubated with $0.5 \mathrm{~mm} \mathrm{P30} \mathrm{(50} \mu \mathrm{l}$ ) on ice for $3 \mathrm{~h}$; (2) $50 \mu$ of $22 \mathrm{~L}$-infected brain homogenate was incubated with $1 \mathrm{~mm} \mathrm{P30}$ at room temperature for $2 \mathrm{~h}$; (3) $50 \mu$ of $22 \mathrm{~L}$-infected brain homogenate was incubated with 1-3 mм P30 (corresponding to 100-300 $\mu$ of P30 at $5 \mathrm{~mm}$ ) at room temperature for $1 \mathrm{~h}$. At the end of the incubation time, samples were digested with proteinase $\mathrm{K}$ before analysis of $\mathrm{PrP}^{\mathrm{Sc}}$ accumulation by Western blotting according to the protocol described in Figure 2. CTR, Negative control, untreated 22L-infected brain homogenate; DM, 22L-infected brain homogenate incubated with $200 \mu \mathrm{l}$ of DMSO alone. C, Native gel experiments did not show any P30-induced oligomers above dimers. Fifty microliters of $22 \mathrm{~L}$-infected brain homogenate were incubated with $1.5 \mathrm{~mm} \mathrm{P30}$ or A6 (150 $\mu \mathrm{l}$ at $5 \mathrm{~mm}$ ) at room temperature for $1 \mathrm{~h}$. At the end of the incubation time, samples were digested with proteinase $K$ for $1 \mathrm{~h}$ and reaction was stopped with Complete (Roche). Fifty microliters of the mixture were mixed with an equal volume of denaturating loading buffer for fractionation. Then samples were charged on a native gel (Criterion Precast Tris-HCl; Bio-Rad), and the migration was done using Tris-glycine buffer (Bio-Rad). Proteins were transferred onto PVDF membrane and revealed using SAF mix antibodies. CTR, Untreated 22L-infected brain homogenate; DM, 22L-infected brain homogenate incubated with $150 \mu$ l of DMSO. D, PrP(27-30) oligomers induced by thienyl pyrimidine compounds are less resistant to increasing concentrations of proteinase $\mathrm{K}$. Twenty-five microliters of $22 \mathrm{~L}$-infected brain extract were incubated with $1.5 \mathrm{~mm}$ P30 or $75 \mu$ l of DMSO for $1 \mathrm{~h}$ at room temperature. Resistance of PrP(27-30) oligomers to proteinase $\mathrm{K}$ was evaluated using various concentrations of proteinase $K: 0.1,0.2,0.4,0.8$, or $1.2 \mathrm{mg} / \mathrm{ml}$. Samples were digested with proteinase $K$ before Western blotting. Blots were probed with the SAF mix.

homogenates survived longer $(245 \pm 14.8 \mathrm{~d})$ than animals injected with DMSO-treated cell homogenates $(199 \pm 7.1 \mathrm{~d})$ (Fig. $7 B)$. Statistical analyses were not possible because of the low number of animals per group; however, the experiment was repeated with brain homogenates and validated (see Fig. 9). This result shows that P30 drug reduces the infectious titer of prion-infected cells. These experiments were performed only with P30 because A6 exhibited poor solubility that could have been detrimental for injection into the brain.

Thienyl pyrimidine compounds trap $\mathrm{PrP}^{\mathrm{Sc}}$ in cell lysates and brain homogenates infected with prions

To test whether the oligomeric activity of the thienyl pyrimidine compounds required the in vivo cell machinery or relied on direct interaction, fresh N2a58/22L cell lysates were incubated with quantities of P30 that were equivalent to those used to treat cells with 20-40 $\mu \mathrm{M}$ P30 for $4 \mathrm{~d}$ (see Fig. 3, dose-response curve). After a $1 \mathrm{~h}$ incubation, cellular lysates were digested with $\mathrm{PK}$, and oligomeric activity was assessed by Western blotting. P30 directly induced formation of $\operatorname{PrP}(27-30)$ dimers and trimers in cell lysates in a dosedependent and reproducible manner (Fig. $8 A)$. This result suggests that the mechanism of action of P30 does not require the in vivo cell machinery but rather is a direct effect. In addition, if the mechanism of action is free from the cell machinery, we should also be able to observe $\operatorname{PrP}(27-30)$ oligomers in brain homogenates of mice infected with the scrapie strain 22L after treatment with the P30 drug. To this aim, several experimental parameters were tested (i.e., quantity of 22L-infected brain extracts, volume of P30, and incubation times) to finally determine that a short incubation time $(1 \mathrm{~h})$, small quantities of brain homogenates $(50 \mu \mathrm{g})$, and at least $1 \mathrm{~mm}$ P30 induced $\operatorname{PrP}(27-30)$ oligomers in 22L-infected brain homogenates (Fig. $8 B$ ).

To test whether non-denaturating conditions could allow us to see oligomers of higher molecular weight, we performed experiments on native gels. A first assay was done using native loading and migration buffers without SDS and DTT but samples stacked in the wells of the native gel (data not shown). A second assay was done using a denaturating loading buffer to fractionate proteins, and the migration was performed on native gel using a native migration buffer without SDS and DTT (Fig. 8C). We did not observe differences with SDS-PAGE gel in the migration pattern, because higher-molecular-weight oligomers did not appear. This last experiment suggests that the two compounds did not increase the total aggregated state of the $\operatorname{PrP}{ }^{\mathrm{Sc}}$.

Furthermore, we evaluated the resistance to PK by using various concentrations of PK on brain homogenates previously treated with P30 drug or DMSO for $1 \mathrm{~h}$ at room temperature. A first experiment using a range of concentrations from 10 to $100 \mu \mathrm{g} / \mathrm{ml}$ showed no differences in the levels of monomers and dimers of $\operatorname{PrP}(27-30)$ (data not shown). A second experiment was performed with higher concentrations of PK, from 0.1 to $1.2 \mathrm{mg} / \mathrm{ml}$ (Fig. $8 D$ ). When we used an increasing concentration of $\mathrm{PK}$, no difference was observed in the quantity of $\operatorname{Pr} P(27-30)$ monomers between the samples pretreated with P30 and those treated with DMSO (Fig. $8 D$, immunoblot). However, the signal of $\operatorname{Pr} P(27-30)$ dimers disappeared in the presence of $1.2 \mathrm{mg} / \mathrm{ml} \mathrm{PK}$, indicating that these species are more sensitive to high concentrations of PK.

\section{Survival time is increased in mice infected with prions treated} with P30

Previously, we showed that the oligomeric activity induced by thienyl pyrimidine drugs could diminish the infectivity of prioninfected cells; thus, we checked whether the P30 drug could also diminish $\mathrm{PrP}^{\mathrm{Sc}}$ infectivity in brain homogenates. To test this hypothesis, 22L-infected brain homogenates were incubated with 
$1.5 \mathrm{~mm}$ P30 or $150 \mu \mathrm{l}$ of DMSO for $2 \mathrm{~h}$ and then injected into the brains of healthy Swiss mice using a stereotaxic frame. These experiments were performed only with P30 because of the poor solubility of A6. Immunoblot analysis of P30-treated inoculi was performed to check for oligomeric activity before intracerebral injection (Fig. 9A). Mice inoculated with 22Linfected brain homogenates treated with P30 lived significantly longer than those inoculated with 22L-infected homogenates treated with DMSO alone (Fig. 9B). The mean \pm SD survival time of mice injected with P30-treated inoculi was $167 \pm$ $2.3 \mathrm{~d}(n=10)$ compared with $154 \pm 1.3 \mathrm{~d}$ $(n=9)$ for control mice (DMSO-treated inoculum), which was statistically significant according to the nonparametric Wilcoxon's test ( $W=7, p=0.0019)$. KaplanMeier survival curves showed that half of the mice infected with P30-treated inoculi survived for up to $172 \mathrm{~d}$. This result shows that oligomers induced by $\mathrm{P} 30$ reduces the infectious titer of prion-infected inoculi. Analysis of brain homogenates from mice inoculated with P30-treated homogenates did not show the presence of oligomeric bands as in the inoculum, suggesting that we did not create a new prion strain (Fig. 9C). Histopathological analysis of brain tissues at the terminal stage of disease revealed no difference in spongiosis and astrocytic gliosis in mice that were inoculated with homogenates treated with P30 or with DMSO (Fig. 9D).

\section{Discussion}

$\mathrm{PrP}^{\mathrm{Sc}}$ is a key element in the pathogenesis of prion diseases and thus represents privileged targets for the development of therapeutic strategies to combat these fatal transmissible agents. Our objective was to target $\operatorname{PrP}^{\mathrm{Sc}}$ species with small molecules with the idea of blocking $\mathrm{PrP}^{\mathrm{Sc}}$ species to prevent their recycling in the pathological aggregation pathway. Our combined approach of virtual and drug screenings showed that thienyl pyrimidine compounds trap the pathological isoform $\mathrm{PrP}^{\mathrm{Sc}}$ (either small $\mathrm{PrP}^{\mathrm{Sc}}$ entities or large aggregates present in cells or brain homogenates), which then become SDS-resistant $\operatorname{PrP}(27-30)$ dimers and trimers after $\mathrm{PK}$ digestion and denaturation. The resulting effect is a small decrease in prion infectivity. Additional experiments to gain insights into the mode of action of two of these thienyl pyrimidine compounds (P30 and A6) showed the following: (1) their oligomer-inducing activity is observed only in the presence of infectious material and appears to be $\mathrm{PrP}^{\mathrm{Sc}}$ specific; (2) the oligomer-inducing effect on cells treated with thienyl pyrimidine compounds remains stable even after termination of the treatment with P30 or A6; (3) brain homogenates treated with these compounds also exhibit dimers of PrP27-30; and (4) this oligomeric-induced activity is free from the in vivo cell machinery, suggesting a direct effect.

For augmentation of $\operatorname{Pr} \mathrm{P}(27-30)$ signal and diminution of prion infectivity, how should the apparent contradiction be reconciled? For two decades, the search for new anti-prions drugs
B

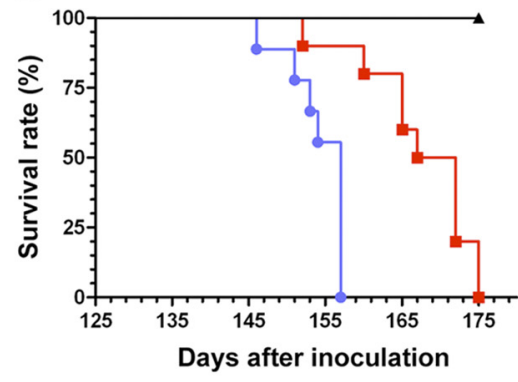

D

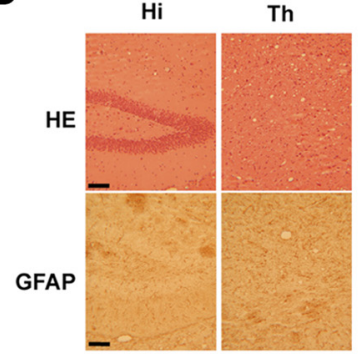

$(22 L+D M)$

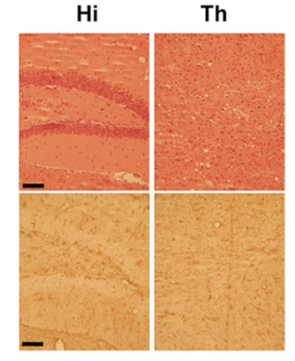

$(22 L+P 30)$
Figure 9. P30 increased survival time in mice injected with brain homogenates infected with the $22 \mathrm{~L}$ strain. $A$, Fifty microliters

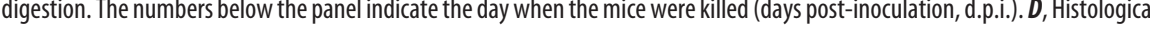
with anti-GFAP antibodies as a marker of astrocytic gliosis. Scale bars, $10 \mu \mathrm{m}$.

using prion-infected cells or in vitro assays focused on decreasing levels of $\operatorname{PrP}(27-30)$, the main marker of the prion diseases (Fig. 1). In contrast, one can speculate that compounds favoring the appearance of $\operatorname{PrP}(27-30)$ species would increase infectivity and/or toxicity, which is probably the main reason that screening for "anti-prion" drugs promoting oligomers of the $\operatorname{PrP}(27-30)$ signal has not yet been explored. In one way, an increase in the level of the monomeric $\operatorname{PrP}(27-30)$ marker would strongly suggest an amplification of prion and infectivity. Indeed, Murayama et al. (2010) succeeded in amplifying the monomeric $\operatorname{PrP}(27-30)$ from bovine prions when they added sulfated dextran during the PMCA method used for diagnostic purposes (Murayama et al., 2010). In contrast, in the present study, we searched for drugs promoting the formation of small oligomers of $\operatorname{Pr} \mathrm{P}(27-30)$ because of a suggested stabilization of $\mathrm{PrP}^{\mathrm{Sc}}$ associated with the idea of trapping prion infectivity. Indeed, many recent studies aiming to characterize the conformational stability of various prion strains to elucidate the molecular aspects of PrP conformation showed a direct relationship between stability and incubation time. Colby et al. (2009) demonstrated that stable recombinant amyloids produced a more stable prion strain, leading to the longest incubation time, whereas more labile amyloids generated less stable strains and shorter incubation times (Colby et al., 2009). Guanidine hydrochloride experiments on cells preincubated with thienyl pyrimidine compounds have shown that these drugs do not ostensibly induce a conformational stability of the inoculum. They could interact and stabilize a small subpopulation of infectious $\mathrm{PrP}^{\mathrm{Sc}}$ molecules, but this effect is not represen- 
tative of the overall population, and the conformational stability thus cannot be observed (Colby et al., 2009). This hypothesis could explain why we obtained a minor decrease in infectivity. It is likely that some analogs of P30 that exhibit a more potent activity could completely block the infectivity of the inoculum, and we will focus our efforts in this direction.

Although we could determine that the thienyl pyrimidine compounds do not need the in vivo cell machinery to form $\operatorname{PrP}(27-30)$ dimers and trimers, their mechanism of action remains to be clarified. In addition, we do not know yet which $\mathrm{PrP}^{\mathrm{Sc}}$ molecular species are targeted. We thus propose two possible hypotheses.

(1) Thienyl pyrimidine compounds could bind to preexisting $\operatorname{PrP}^{\mathrm{Sc}}$ dimers and trimers. $\operatorname{PrP}^{\mathrm{Sc}}$ dimers and trimers could be transitory and unstable species (DeMarco et al., 2006; Silveira et al., 2005), possibly referring to pre-amyloid states (Stöhr et al., 2008). Indeed, from electron crystallographic studies established using $\mathrm{PrP}^{\mathrm{Sc}}$ purified from infected brain homogenates, two models of prion proto-fibril propagation are currently emerging: the $\beta$-helix model and the spiral model. Both models contain oligomeric discs composed of $\mathrm{PrP}^{\mathrm{Sc}}$ trimers that can assemble into proto-fibrils (Wille et al., 2002; DeMarco and Daggett, 2004; Govaerts et al., 2004; DeMarco et al., 2006). The true existence of such small oligomeric species is a matter of much debate, but we cannot exclude that possibility. We hypothesize that, during binding of thienyl pyrimidine drugs, dimers and trimers of $\operatorname{Pr} \mathrm{P}^{\mathrm{sc}}$ are diverted from the pathological aggregation pathway and trapped into a thermodynamic landscape that is not competent for additional propagation of infection (El Moustaine et al., 2008). After the PK digestion assay, those putative P30-stabilized dimers and trimers of $\mathrm{PrP}^{\mathrm{Sc}}$ become SDS-resistant (PrP27-30) dimers and trimers under denaturation conditions. In addition, dimers and trimers of $\operatorname{PrP}^{\mathrm{Sc}}$ might represent a minority of the heterogeneous infectious $\operatorname{PrP}^{\mathrm{Sc}}$ species present in the inoculum. Thus, trapping these small oligomers with drugs can block only a fraction of the prion infectivity in the inoculum. This hypothesis correlates well with the results of our in vivo experiments in which we observed a partial reduction in prion infectivity.

(2) The thienyl pyrimidine compounds could cross-link $\operatorname{PrP}^{\mathrm{Sc}}$ subunits belonging to amyloidogenic structures. To check this hypothesis, we performed in vitro experiments using recombinant mouse PrP fibrils incubated with thienyl pyrimidine compounds and showed that P30 does not cross-link amyloid fibrils or influence the kinetics of amyloid fibril formation (Fig. $5 A, B$ ). Despite this result, we cannot completely rule out this hypothesis because recombinant fibrils substantially differ from natural fibrils (Wille et al., 2009). Wille et al. have observed some repeated units along the natural fiber axis purified from brain-derived prions that were barely observed in recPrP fibrils, suggesting a key role in infectivity. Our compounds could conceivably target these specific structures.

Because of their specific effect on $\operatorname{PrP}^{\mathrm{Sc}}$, the thienyl pyrimidine compounds have interesting potential applications in the field of detection assays and/or decontamination procedure. In addition, $\operatorname{PrP}(27-30)$ dimers or trimers observed with thienyl pyrimidine compounds could also represent a new marker of prion disease in biological fluids. In the therapeutic field, trapping the main marker of prion diseases, the $\operatorname{PrP}(27-30)$, into dimeric/trimeric forms represents a breakthrough in the identification of new anti-prion drugs. Furthermore, this approach opens new avenues for the development of new drug-screening assays. We believe that the combination of several anti-prion drugs that target different intermediates of the prion replication cycle would be a better way to prevent prion propagation and to possibly identify a cure for prion-related diseases. The strategy, which consists of stabilizing the main marker of prion diseases into small oligomers, could also be envisaged for use in the treatment of other proteinopathies that lead to neurodegenerative disorders, such as Alzheimer's and Huntington diseases.

\section{Notes}

For results of the first screening, see Table S1. Supplemental material for this article is available by e-mailing Dr. Perrier at veronique.perrier@univ-montp2.fr, or at http://mmdn.um2.fr starting December 2011. This material has not been peer reviewed.

\section{References}

Adjou KT, Demaimay R, Deslys JP, Lasmézas CI, Beringue V, Demart S, Lamoury F, Seman M, Dormont D (1999) MS-8209, a water-soluble amphotericin B derivative, affects both scrapie agent replication and PrPres accumulation in Syrian hamster scrapie. J Gen Virol 80:10791085 .

Andreoletti O (2004) Techniques in prion research (methods and tools in biosciences and medicine), pp 82-96. Basel: Birkhäuser Basel.

Arkin MR, Wells JA (2004) Small-molecule inhibitors of protein-protein interactions: progressing towards the dream. Nat Rev Drug Discov 3:301-317.

Beringue V, Adjou KT, Lamoury F, Maignien T, Deslys JP, Race R, Dormont D (2000) Opposite effects of dextran sulfate 500, the polyene antibiotic MS-8209, and Congo red on accumulation of the protease-resistant isoform of $\operatorname{PrP}$ in the spleens of mice inoculated intraperitoneally with the scrapie agent. J Virol 74:5432-5440.

Bocharova OV, Breydo L, Parfenov AS, Salnikov VV, Baskakov IV (2005) In vitro conversion of full-length mammalian prion protein produces amyloid form with physical properties of $\operatorname{PrP}(\mathrm{Sc})$. J Mol Biol 346:645-659.

Breydo L, Makarava N, Baskakov IV (2008) Methods for conversion of prion protein into amyloid fibrils. Methods Mol Biol 459:105-115.

Carlson GA, Kingsbury DT, Goodman PA, Coleman S, Marshall ST, DeArmond S, Westaway D, Prusiner SB (1986) Linkage of prion protein and scrapie incubation time genes. Cell 46:503-511.

Caughey B, Lansbury PT (2003) Protofibrils, pores, fibrils, and neurodegeneration: separating the responsible protein aggregates from the innocent bystanders. Annu Rev Neurosci 26:267-298.

Chevallet M, Luche S, Rabilloud T (2006) Silver staining of proteins in polyacrylamide gels. Nat Protoc 1:1852-1858.

Colby DW, Giles K, Legname G, Wille H, Baskakov IV, DeArmond SJ, Prusiner SB (2009) Design and construction of diverse mammalian prion strains. Proc Natl Acad Sci U S A 106:20417-20422.

Daude N, Marella M, Chabry J (2003) Specific inhibition of pathological prion protein accumulation by small interfering RNAs. J Cell Sci 116:2775-2779.

DeMarco ML, Daggett V (2004) From conversion to aggregation: protofibril formation of the prion protein. Proc Natl Acad Sci U S A 101:2293-2298.

DeMarco ML, Silveira J, Caughey B, Daggett V (2006) Structural properties of prion protein protofibrils and fibrils: an experimental assessment of atomic models. Biochemistry 45:15573-15582.

El Moustaine D, Perrier V, Smeller L, Lange R, Torrent J (2008) Full-length prion protein aggregates to amyloid fibrils and spherical particles by distinct pathways. FEBS J 275:2021-2031.

Govaerts C, Wille H, Prusiner SB, Cohen FE (2004) Evidence for assembly of prions with left-handed beta-helices into trimers. Proc Natl Acad Sci U S A 101:8342-8347.

Jones S, Thornton JM (1997) Prediction of protein-protein interaction sites using patch analysis. J Mol Biol 272:133-143.

Kellenberger E, Springael JY, Parmentier M, Hachet-Haas M, Galzi JL, Rognan D (2007) Identification of nonpeptide CCR5 receptor agonists by structure-based virtual screening. J Med Chem 50:1294-1303.

Kim YS, Carp RI, Callahan SM, Wisniewski HM (1987) Incubation periods and survival times for mice injected stereotaxically with three scrapie strains in different brain regions. J Gen Virol 68:695-702.

Ludewigs H, Zuber C, Vana K, Nikles D, Zerr I, Weiss S (2007) Therapeutic approaches for prion disorders. Expert Rev Anti Infect Ther 5:613-630. 
Murayama Y, Yoshioka M, Masujin K, Okada H, Iwamaru Y, Imamura M, Matsuura Y, Fukuda S, Onoe S, Yokoyama T, Mohri S (2010) Sulfated dextrans enhance in vitro amplification of bovine spongiform encephalopathy $\operatorname{PrP}(\mathrm{Sc})$ and enable ultrasensitive detection of bovine $\operatorname{PrP}(\mathrm{Sc})$. PLoS One 5.pii:e13152.

Nishida N, Harris DA, Vilette D, Laude H, Frobert Y, Grassi J, Casanova D, Milhavet O, Lehmann S (2000) Successful transmission of three mouseadapted scrapie strains to murine neuroblastoma cell lines overexpressing wild-type mouse prion protein. J Virol 74:320-325.

Paxinos G, Franklin K (1997) The mouse brain in stereotaxic coordinates. San Diego: Academic.

Perrier V, Kaneko K, Safar J, Vergara J, Tremblay P, DeArmond SJ, Cohen FE, Prusiner SB, Wallace AC (2002) Dominant-negative inhibition of prion replication in transgenic mice. Proc Natl Acad Sci U S A 99:13079-13084.

Perrier V, Solassol J, Crozet C, Frobert Y, Mourton-Gilles C, Grassi J, Lehmann S (2004) Anti-PrP antibodies block PrPSc replication in prioninfected cell cultures by accelerating PrPC degradation. J Neurochem 89:454-463.

Prusiner SB (1982) Novel proteinaceous infectious particles cause scrapie. Science 216:136-144.

Rudyk H, Vasiljevic S, Hennion RM, Birkett CR, Hope J, Gilbert IH (2000) Screening Congo Red and its analogues for their ability to prevent the formation of PrP-res in scrapie-infected cells. J Gen Virol 81:1155-1164.

Saborio GP, Permanne B, Soto C (2001) Sensitive detection of pathological prion protein by cyclic amplification of protein misfolding. Nature 411:810-813.

Scott M, Foster D, Mirenda C, Serban D, Coufal F, Wälchli M, Torchia M, Groth D, Carlson G, DeArmond SJ, Westaway D, Prusiner SB (1989) Transgenic mice expressing hamster prion protein produce speciesspecific scrapie infectivity and amyloid plaques. Cell 59:847-857.

Silveira JR, Raymond GJ, Hughson AG, Race RE, Sim VL, Hayes SF, Caughey
B (2005) The most infectious prion protein particles. Nature 437: 257-261.

Simoneau S, Rezaei H, Salès N, Kaiser-Schulz G, Lefebvre-Roque M, Vidal C, Fournier JG, Comte J, Wopfner F, Grosclaude J, Schätzl H, Lasmézas CI (2007) In vitro and in vivo neurotoxicity of prion protein oligomers. PLoS Pathog 3:e125.

Stöhr J, Weinmann N, Wille H, Kaimann T, Nagel-Steger L, Birkmann E, Panza G, Prusiner SB, Eigen M, Riesner D (2008) Mechanisms of prion protein assembly into amyloid. Proc Natl Acad Sci U S A 105:2409-2414.

Supattapone S, Nguyen HO, Cohen FE, Prusiner SB, Scott MR (1999) Elimination of prions by branched polyamines and implications for therapeutics. Proc Natl Acad Sci U S A 96:14529-14534.

Touil F, Pratt S, Mutter R, Chen B (2006) Screening a library of potential prion therapeutics against cellular prion proteins and insights into their mode of biological activities by surface plasmon resonance. J Pharm Biomed Anal 40:822-832.

Verdonk ML, Cole JC, Hartshorn MJ, Murray CW, Taylor RD (2003) Improved protein-ligand docking using GOLD. Proteins 52:609-623.

Wang F, Wang X, Yuan CG, Ma J (2010) Generating a prion with bacterially expressed recombinant prion protein. Science 327:1132-1135.

White MD, Farmer M, Mirabile I, Brandner S, Collinge J, Mallucci GR (2008) Single treatment with RNAi against prion protein rescues early neuronal dysfunction and prolongs survival in mice with prion disease. Proc Natl Acad Sci U S A 105:10238-10243.

Wille H, Michelitsch MD, Guenebaut V, Supattapone S, Serban A, Cohen FE, Agard DA, Prusiner SB (2002) Structural studies of the scrapie prion protein by electron crystallography. Proc Natl Acad Sci USA 99:3563-3568.

Wille H, Bian W, McDonald M, Kendall A, Colby DW, Bloch L, Ollesch J, Borovinskiy AL, Cohen FE, Prusiner SB, Stubbs G (2009) Natural and synthetic prion structure from X-ray fiber diffraction. Proc Natl Acad Sci U S A 106:16990-16995. 